\title{
Materialia
}

\section{Profilometry-based Indentation to obtain Stress-Strain Curves from Anisotropic Superalloy Components made by Additive Manufacturing \\ --Manuscript Draft--}

\begin{tabular}{|c|c|}
\hline Manuscript Number: & MTLA-D-20-00710R1 \\
\hline Article Type: & Full Length Article \\
\hline Keywords: & $\begin{array}{l}\text { Indentation plastometry; inverse finite element method; nickel superalloy; additive } \\
\text { manufacturing }\end{array}$ \\
\hline Corresponding Author: & $\begin{array}{l}\text { Trevor William Clyne, PhD } \\
\text { Cambridge University } \\
\text { Cambridge, UNITED KINGDOM }\end{array}$ \\
\hline First Author: & Yuanbo T Tang, PhD \\
\hline \multirow[t]{6}{*}{ Order of Authors: } & Yuanbo T Tang, PhD \\
\hline & Jimmy E Campbell, PhD \\
\hline & Max Burley, PhD \\
\hline & James Dean, PhD \\
\hline & Roger C Reed, PhD \\
\hline & Bill Clyne, PhD \\
\hline Abstract: & $\begin{array}{l}\text { This investigation concerns superalloy samples produced by an additive manufacturing } \\
\text { procedure. Microstructural examination confirmed that they exhibited a columnar grain } \\
\text { structure, with the grains elongated in the growth ("build") direction and exhibiting a } \\
\text { strong texture involving alignment of }<100>\text { parallel to this axis. Samples were tensile } \\
\text { tested along both build and transverse directions, being found to be both stiffer and } \\
\text { harder in the latter. This material thus exhibits well-characterized anisotropy, making it } \\
\text { well-suited to study of how this affects outcomes from an indentation-based procedure } \\
\text { for obtaining stress-strain curves. This is termed Profilometry-based Inverse FEM for } \\
\text { Plasticity Parameters from Indentation (PIP). True stress-strain curves obtained using } \\
\text { this methodology were found to be entirely consistent with the directly-measured } \\
\text { curves. Furthermore, it is shown that full 3-D characterization of the indent profiles can } \\
\text { be used to obtain at least a semi-quantitative indication of the nature and strength of } \\
\text { the plastic anisotropy. This constitutes a significant advance in the context of a } \\
\text { technique that could have a transformative effect on mechanical testing procedures. }\end{array}$ \\
\hline \multirow[t]{4}{*}{ Suggested Reviewers: } & $\begin{array}{l}\text { Philip Withers, PhD } \\
\text { Professor, University of Manchester Institute of Science and Technology: The } \\
\text { University of Manchester } \\
\text { p.j.withers@manchester.ac.uk } \\
\text { Authority on Mechanics }\end{array}$ \\
\hline & $\begin{array}{l}\text { Allan Matthews, PhD } \\
\text { Professor, University of Manchester Institute of Science and Technology: The } \\
\text { University of Manchester } \\
\text { allan.matthews@manchester.ac.uk } \\
\text { Authority on Surface Engineering }\end{array}$ \\
\hline & $\begin{array}{l}\text { Dierk Raabe, PhD } \\
\text { Professor, Max-Planck-Institut fur Eisenforschung GmbH } \\
\text { d.raabe@mpie.de } \\
\text { Authority on Metallurgy }\end{array}$ \\
\hline & $\begin{array}{l}\text { Russel Goodall, PhD } \\
\text { Associate Professor, The University of Sheffield } \\
\text { r.goodall@sheffield.ac.uk } \\
\text { Authority on Indentation }\end{array}$ \\
\hline Op & \\
\hline
\end{tabular}




\section{University of} Cambridge

Department of Materials Science \& Metallurgy

27 Charles Babbage Road Cambridge CB3 OFS

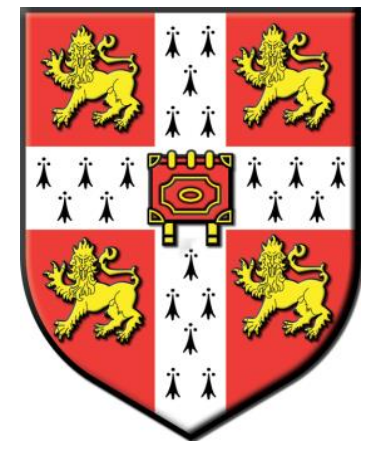

Prof TW Clyne FREng Professor of Mechanics of Materials

Director of Gordon Laboratory Helmholtz International Fellow

office

00441223334332

lab 00441223334340

reception 00441223334300

twc10@cam.ac.uk

www.ccg.msm.cam.ac.uk/

Editor

Materialia

$12^{\text {th }}$ January 2021

\section{Profilometry-based Indentation to obtain Stress-Strain Curves from Anisotropic Superalloy Components made by Additive} Manufacturing

YT Tang, JE Campbell, M Burley, J Dean, RC Reed \& TW Clyne ${ }^{\dagger}$

This is a revised version of the paper, which has been modified following the recommendations of the reviewer. Please note that a minor change has been made to the title.

Best Wishes

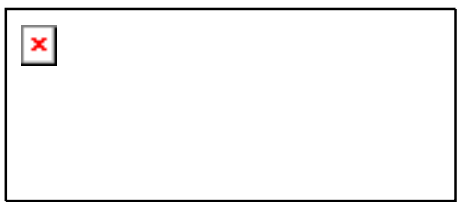

Bill 
Re-submitted to Materialia, Jan. 2021

\section{Profilometry-based Indentation Plastometry to obtain Stress- Strain Curves from Anisotropic Superalloy Components made by Additive Manufacturing}

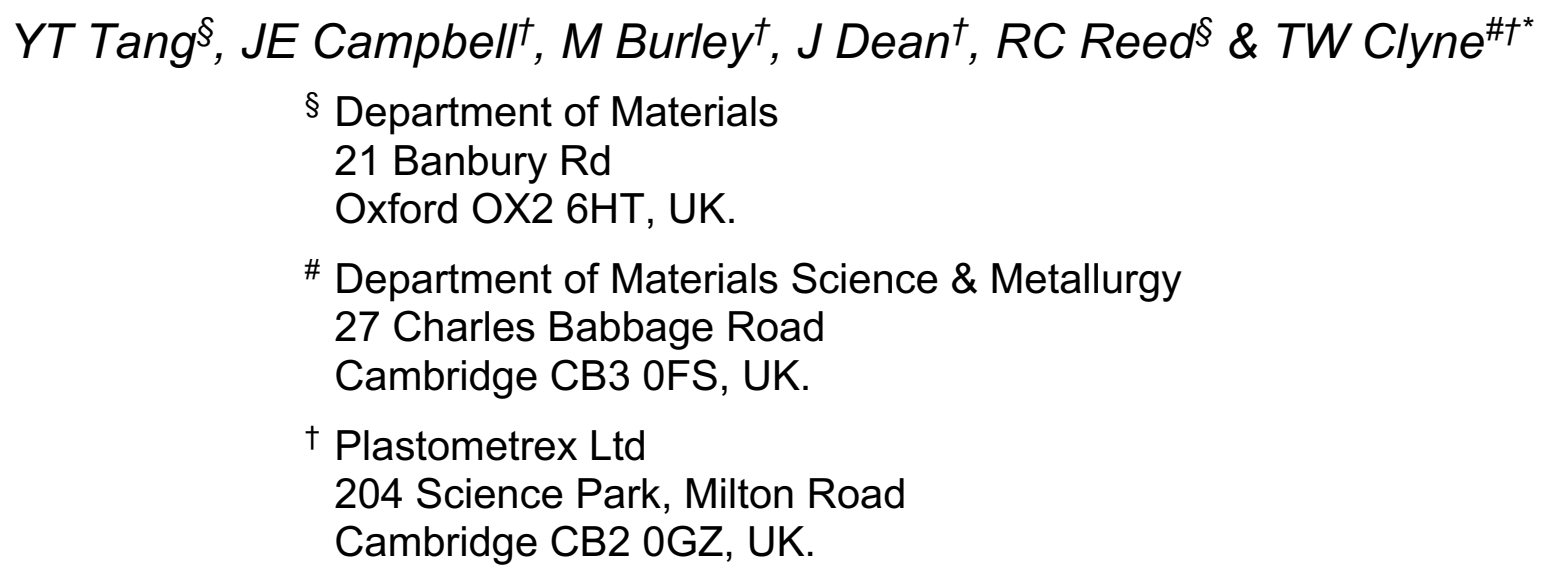

\section{Abstract}

This investigation concerns superalloy samples produced by an additive manufacturing procedure. Microstructural examination confirmed that they exhibited a columnar grain structure, with the grains elongated in the growth ("build") direction and exhibiting a strong texture involving alignment of $<100\rangle$ parallel to this axis. Samples were tensile tested along both build and transverse directions, being found to be both stiffer and harder in the latter. This material thus exhibits well-characterized anisotropy, making it well-suited to study of how this affects outcomes from an indentation-based procedure for obtaining stress-strain curves. This is termed Profilometry-based Inverse FEM for Plasticity Parameters from Indentation (PIP). True stress-strain curves obtained using this methodology were found to be entirely consistent with the directly-measured curves. Furthermore, it is shown that full 3-D characterization of the indent profiles can be used to obtain at least a semi-quantitative indication of the nature and strength of the plastic anisotropy. This constitutes a significant advance in the context of a technique that could have a transformative effect on mechanical testing procedures.

Keywords: Indentation plastometry; inverse finite element method (FEM); nickel superalloy; additive manufacturing.

\section{Introduction}

There is extensive activity [1-7] related to additive manufacturing ("3-D printing"), which is attractive for the production of (relatively small) components with complex shapes, to a high level of precision. Initial developments largely related to polymeric materials, but it has become clear that it can also be successfully applied to various metals. In particular, there is considerable interest [8-15] in Ni-based superalloys made via AM, with quite extensive study [16-21] of their mechanical properties. There are several variants of the process, but a

\footnotetext{
*tel: 00441223 867995: e-mail: b.clyne@plastometrex.com
} 
common feature is the directional layer-by-layer build-up of consolidated material, involving close control over the relevant transport phenomena (heat transfer, mass movement and fluid flow). The procedure commonly involves powder feedstock and a directed heat source (usually a laser or an electron beam).

One of the most important areas to be addressed concerns the relationships between processing conditions and mechanical properties. These have been established over an extended period for conventional metal processing operations such as casting, rolling, forging, powder sintering etc. However, additive manufacturing differs from these, although it often incorporates features of several of them. Moreover, there are often local variations in consolidation conditions, and hence in microstructure and mechanical properties. There is particular interest in the plasticity response - the yield stress and the work hardening behavior (which also provide insights into the toughness). There is also potential for the directionality of the process to result in these properties being significantly anisotropic (as a result of crystallographic texture, grain shape anisotropy, alignment of second phase, porosity etc). There has already been work [22] on controlling the texture of additively manufactured superalloy components (by imposing a magnetic field). Of course, such effects can also arise in conventionally-processed metallic components, but the relatively small scale of many additively manufactured components, and the complexity of their shape, means that growth conditions and microstructure may change over short distances. This is challenging in terms of mechanical property characterization, since tensile testing on a small scale presents certain difficulties, while hardness is not an unambiguous or well-defined "property". Nevertheless, in order to capitalize in various directions on the potential of additive manufacturing, detailed information concerning the linkages between processing conditions, microstructure and mechanical properties is essential.

In fact, a testing methodology has recently been developed with a capability for obtaining meaningful information about plasticity (ie the uniaxial stress-strain relationship) from testing (indentation) of a small local area. This is now termed Profilometry-based Inverse FEM for Plasticity Parameters from Indentation (PIP). Its emergence is the outcome of an extended period of research and development [23-29]. It has already been applied locally to a Ni-based superalloy, in a study aimed at obtaining the stress-strain response of a thin plasma sprayed layer [30]. It is based on iterative FEM simulation of the indentation process, with the plasticity parameters (in a constitutive law) being repeatedly changed until optimum agreement is reached between experimental and predicted outcomes. While the outcome that was used in much early work was the load-displacement plot, it has become clear that using the residual indent profile is often preferable. An obvious advantage of this is that it at least offers potential for investigation of plastic anisotropy (whereas using load-displacement data does not). This point has been recognized in several indentation-based studies [31-33]

Several important points concerning the optimization of this procedure have recently become clear. One of these [27] is that a spherical indenter is preferable to a "sharp" one. Others include the importance of deforming a volume that is large enough for its mechanical response to be representative of the bulk, which requires it to be a multi-grain assembly and 
typically translates into a need for the indenter radius to be of the order of $1 \mathrm{~mm}$ and the load capability to extend to the $\mathrm{kN}$ range. This means that equipment allowing what is often described as "nano-indention" is unsuitable and a customized loading frame is required. It is also clear that, if the technique is to be routinely employed, then an integrated system is required, incorporating a loading frame, a profilometer and a software package allowing automated convergence on the best fit stress-strain curve. Of course, once that has been established, then FEM simulation of any loading configuration, including a uniaxial tensile test, can readily be carried out. Such an integrated facility is now being produced and sold commercially by Plastometrex Ltd. This facility was used in the work described here.

\section{Experimental Procedures}

\subsection{Additive Manufacturing}

A trial version of the ABD-850AM alloy was used for the current study. The material was first argon gas atomized into powder. This had a median diameter of about $30 \mu \mathrm{m}$. The approximate composition is given in Table $\mathrm{l}$.

\begin{tabular}{|c|c|c|c|c|c|c|c|c|c|c|c|}
\hline \multirow{2}{*}{ Powder } & \multicolumn{10}{|c|}{ Composition (wt.\%) } \\
\cline { 2 - 13 } & Cr & Co & Mo & Al & Ti & Ta & Nb & W & C & B & Ni \\
\hline ABD-850AM & 19.7 & 18.6 & 2.0 & 1.5 & 2.4 & 0.6 & 0.4 & 5.1 & 0.13 & 0.01 & bal. \\
\hline
\end{tabular}

Table I Powder composition.

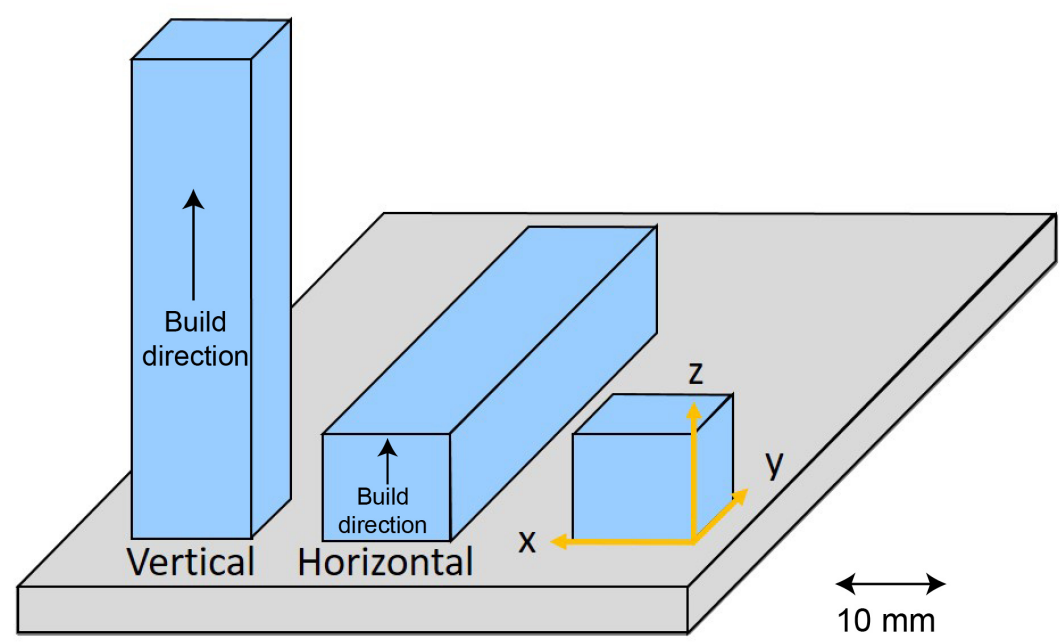

Fig.1 Schematic depiction of the three types of sample produced by additive manufacturing, showing the coordinate system nomenclature.

The additive manufacturing procedure was carried out via powder-bed laser melting, using a Renishaw AM400 machine. The laser was operated in modulated (pulsed) mode, scanning with a meander strategy. The powder bed layer thickness was about $30 \mu \mathrm{m}$. Each layer was built up after rotating by $67^{\circ}$ relative to the previous one and finished [11] with a double pass border scan (to enhance the surface finish). The laser power was $200 \mathrm{~W}$, with a traverse speed of $1.2 \mathrm{~m} \mathrm{~s}^{-1}$. 
Three types of sample were produced: cube, axial cuboid and transverse cuboid. The cube had sides of $10 \mathrm{~mm}$. The cuboids both had dimensions of $10 \mathrm{~mm}$ by $10 \mathrm{~mm}$ by $52 \mathrm{~mm}$. The long axis was the growth direction in one case ("vertical"), while in the other ("horizontal") it was transverse to this. The coordinate nomenclature employed is shown in Fig.1.

\subsection{Sample Preparation and Microstructural Examination}

Both axial $(x-z)$ and transverse $(x-y)$ sections were examined in the bulk part of the cube. Samples were prepared using standard metallographic procedures, with a colloidal silica suspension $(40 \mathrm{~nm})$ finish for 3 mins. A Zeiss Merlin field-emission gun scanning electron microscope (FEG-SEM) was used, the images being obtained using an angular selective backscattered electron (AsB/BSE) detector with an accelerating voltage of $15 \mathrm{kV}$. In addition to the internal microstructure, free surfaces in the immediate vicinity of indents were also examined using a secondary electron (SE) detector. Texture and grain size measurements were carried out via electron backscatter diffraction (EBSD) scans, using a BRUKER e-Flash ${ }^{H R}$ detector and analysed using HKL Channel 5 software.

Furthermore, dislocation structures in the as-fabricated state were revealed using bright field fore-scattered electron (FSE) imaging in the same SEM system, with an on-axis transmission Kikuchi diffraction (TKD) detector. An axial sample was mechanically ground to a thickness of $\sim 150 \mu \mathrm{m}$. This was then converted to an electron-transparent thin foil, using a twin jetting method with $\mathrm{HClO}_{4}$ in methanol under $30 \mathrm{~V}$ at $-40^{\circ} \mathrm{C}$. An accelerating voltage of $30 \mathrm{kV}$ was used, with a $2 \mathrm{nA}$ probe current. Further details are available elsewhere [34].

\subsection{Tensile Testing}

Uniaxial tensile testing was carried out at room temperature, using an Instron electrothermal mechanical testing (ETMT) system. A $5 \mathrm{kN}$ load cell was employed. Testing was carried out under displacement control, at a rate of $5 \mu \mathrm{m} \mathrm{s}^{-1}$ (a strain rate of about $310^{-4} \mathrm{~s}^{-1}$ ). Samples were cut to a dog-bone shape using electro discharge machining (EDM), to give (square section) gauge length dimensions of $1 \mathrm{~mm}$ by $1 \mathrm{~mm}$ by $14 \mathrm{~mm}$. This was done for both "horizontal" and "vertical" samples (see Fig.1). Sample surfaces were ground to 4000 grit (to remove the recast layer). The cross-section was then accurately measured using a micrometer prior to testing. Strain was measured using a video extensometer, with an iMetrum system. Speckle patterns were applied on the surfaces to facilitate tracking. The focus was on the separation of speckles at both ends of the gauge length - ie the (nominal) strain was being measured in the same way as with a clip gauge. All samples were tested until fracture.

\subsection{PIP}

The equipment used in this work was the Indentation Plastometer shown in Fig.2. Four steps are involved in obtaining a tensile stress-strain curve from an indentation test. These are: (a) pushing a hard indenter into the sample with a known force, (b) measuring the (radially-symmetric) profile of the indent, (c) iterative FEM simulation of the test until the best fit set of plasticity parameter values is obtained and (d) using the resultant (true) stress-strain 
relationship in FEM simulation of the tensile test. These steps are described in more detail below.

\subsubsection{Indentation}

The samples for indentation were produced from $10 \mathrm{~mm}$ cubes and had dimensions of $10 \mathrm{~mm}$ by $10 \mathrm{~mm}$ by $5 \mathrm{~mm}$ (in the indentation direction). This was done with the indentation axis being either in the $z$ direction $(x-y$ plane) or in the $y$ direction ( $x-z$ plane). They were mounted and polished (to $1 \mu \mathrm{m}$ finish). They were then placed on the baseplate of the Plastometer and indented with a spherical indenter of radius $1 \mathrm{~mm}$, made of WC-Co cemented carbide. Forces of 1.5, 2.5, 3.5 and $4.5 \mathrm{kN}$ were applied (in the same location), with the profile being measured after each loading operation. The largest load generated a displacement (penetration) of about $200 \mu \mathrm{m}(\delta / R \sim 20 \%)$, and the final indent diameter was around $1 \mathrm{~mm}$.

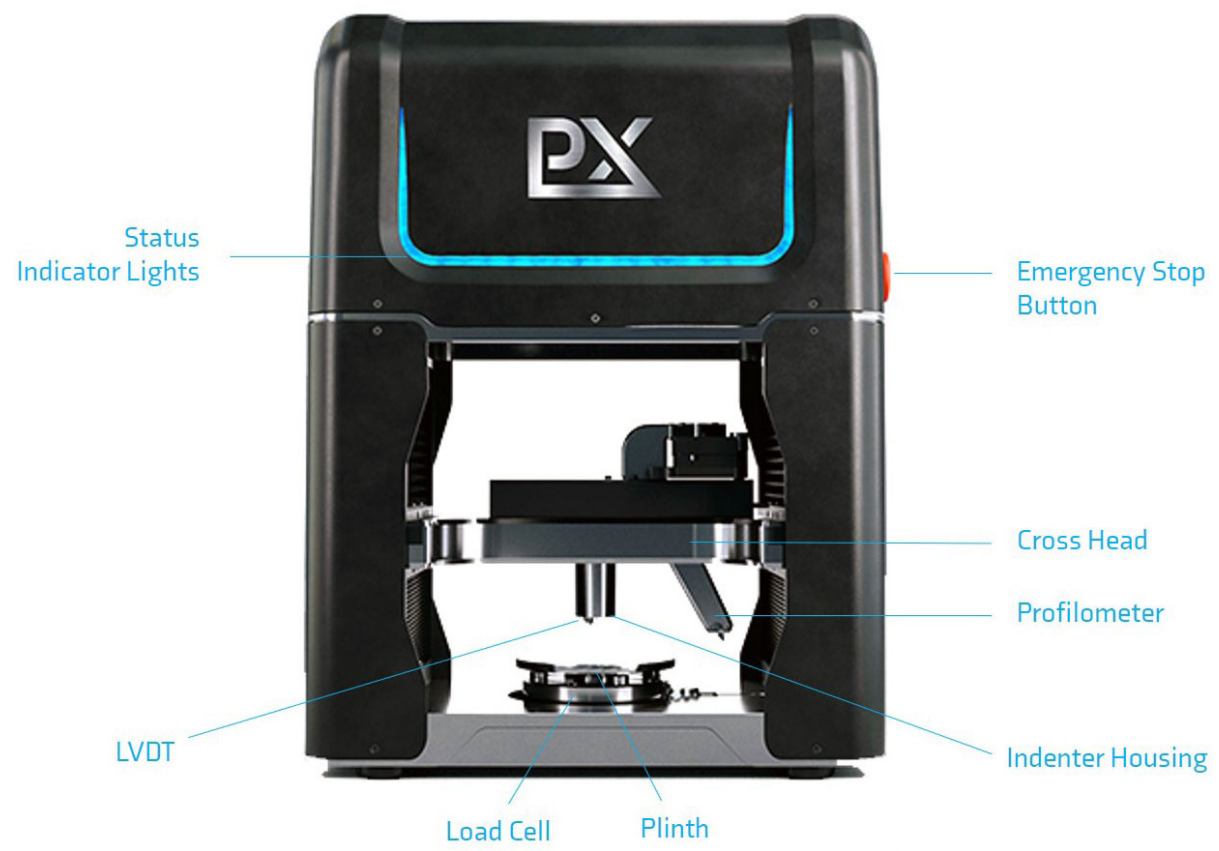

Fig.2 Image of the Plastometer, with the key components labeled.

\subsubsection{Profilometry}

A contacting stylus profilometer is incorporated into the Plastometrex machine. It has a depth resolution of about $1 \mu \mathrm{m}$. Scans were carried out in two perpendicular directions, both through the central axis of the indent. Tilt correction functions were applied to the raw data, based on the far-field parts of the scan being parallel. This procedure is carried out automatically under software control.

\subsubsection{Extraction of Plasticity Parameters}

For any approach involving iterative simulation of a deformation process, the stress-strain relationship (material plasticity response) must be characterized via a (small) set of parameter values. Several expressions are in common use, but the current Plastometrex methodology is based on use of the Voce equation [35] 


$$
\sigma=\sigma_{\mathrm{S}}-\left(\sigma_{\mathrm{S}}-\sigma_{\mathrm{Y}}\right) \exp \left(\frac{-\varepsilon}{\varepsilon_{0}}\right)
$$

where $\sigma$ is the (true) stress, $\varepsilon$ is the (true) strain, $\sigma_{\mathrm{Y}}$ is the yield stress, $\sigma_{\mathrm{s}}$ is a saturation stress and $\varepsilon_{0}$ is a characteristic strain (for the approach of the stress to its saturation level). An expression of this type is consistent with strain hardening being mainly caused by the increasing density of dislocations (impairing their mobility as more jogs, tangles etc are formed), but with a hardening rate that falls off with continued straining (as the dislocation density approaches a saturation level).

The underlying methodology for converging on the best fit set of parameter values, focusing on the residual indent profile as the target outcome, is described in the literature [27, 29], as are details of the boundary conditions imposed during simulation of the indentation procedure. Isotropy is assumed, both elastically and plastically. The elastic constants are required as input data. The Young's modulus was taken to be $200 \mathrm{GPa}$ and the Poisson ratio to be 0.33 . (The outcome of the modeling is not strongly sensitive to these parameters.) In characterizing the goodness-of-fit of the outcome of any particular simulation run, a least squares regression approach [36] was used. This leads to a parameter $S_{\text {red, }}$ which is a dimensionless positive number that tends to zero as the fit becomes perfect. The parameter set giving the lowest value of $S_{\text {red }}$ was extracted. A value below about $10^{-3}$ represents a good fit, while a value around $10^{-4}$ or below corresponds to excellent fit.

\subsubsection{Simulation of Tensile Testing}

This set of plasticity parameter values was then employed during simulation of a tensile test, with the same geometry as that of the experimental test. General details of this modeling are available [29] in the literature. In order to simulate necking (in the centre of the test-piece), a boundary condition is imposed that there is no lateral straining at the ends of the reduced section part of the samples [37-39].

\section{Microstructural Features}

\subsection{Grain Structure}

Information about the grain structure is presented in Figs. 3 and 4. Fig. 3 shows two SEM micrographs of a transverse section, while Fig. 4 comprises EBSD patterns from both types of section. It can be seen in Fig. 3 that there was some evidence of both cracking and porosity. In general, however, the level of both was relatively low. It was noticeable that the cracks tended to form with the crack plane lying in the growth direction. This is further explored in $\S 4.1 .2$. It is in any event clear that there is columnar grain structure, with each grain containing many cells (dendrites). In transverse $(x-y)$ sections, the grain size is relatively small ( $\sim 30-$ $40 \mu \mathrm{m})$ and approximately isotropic. In axial sections, on the other hand, grains are elongated (to hundreds of microns) in the growth $(z)$ direction, while still being of the order of a few tens of microns in the transverse ( $x$ and $y$ ) directions. The texture exhibits a strong tendency for $<001>$ to align parallel to the growth direction, which is about 3.6 times more frequently observed than random orientations. 

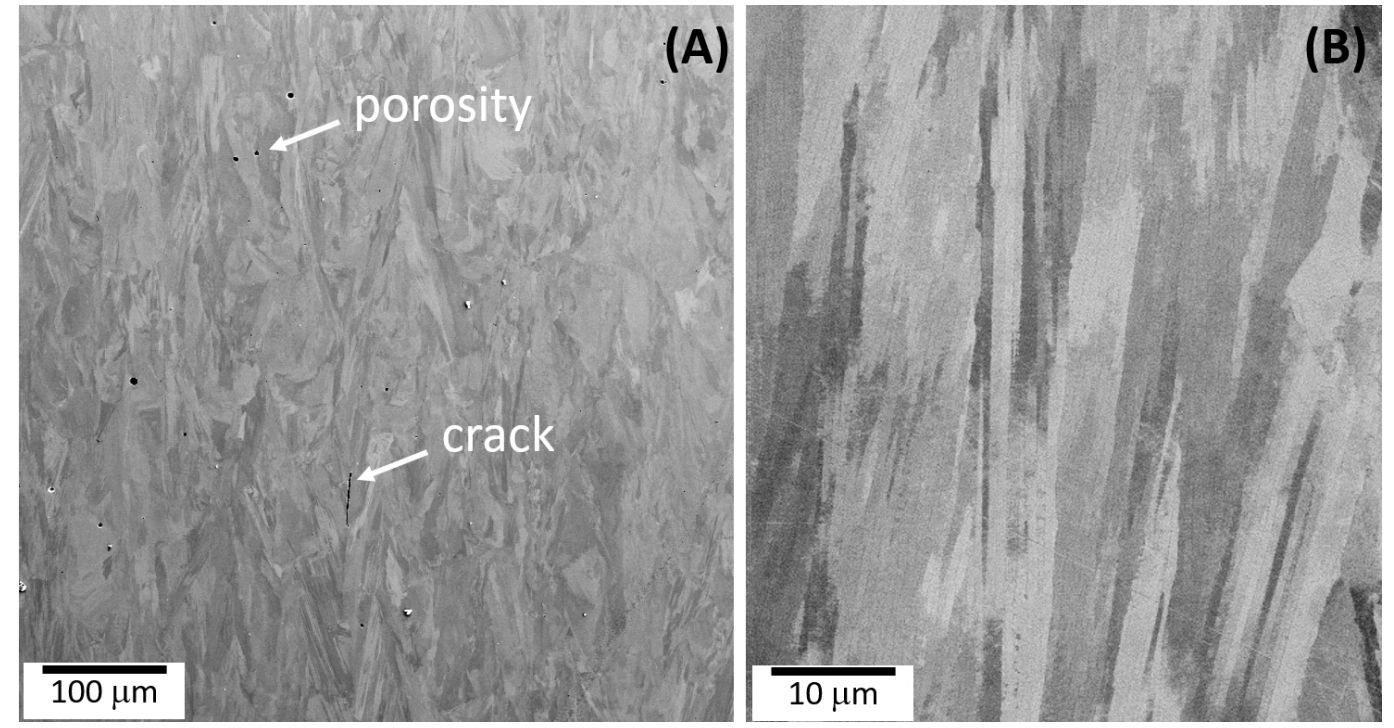

Fig. 3 SEM images of the $x-z$ plane, at (a) low and (b) high magnification.
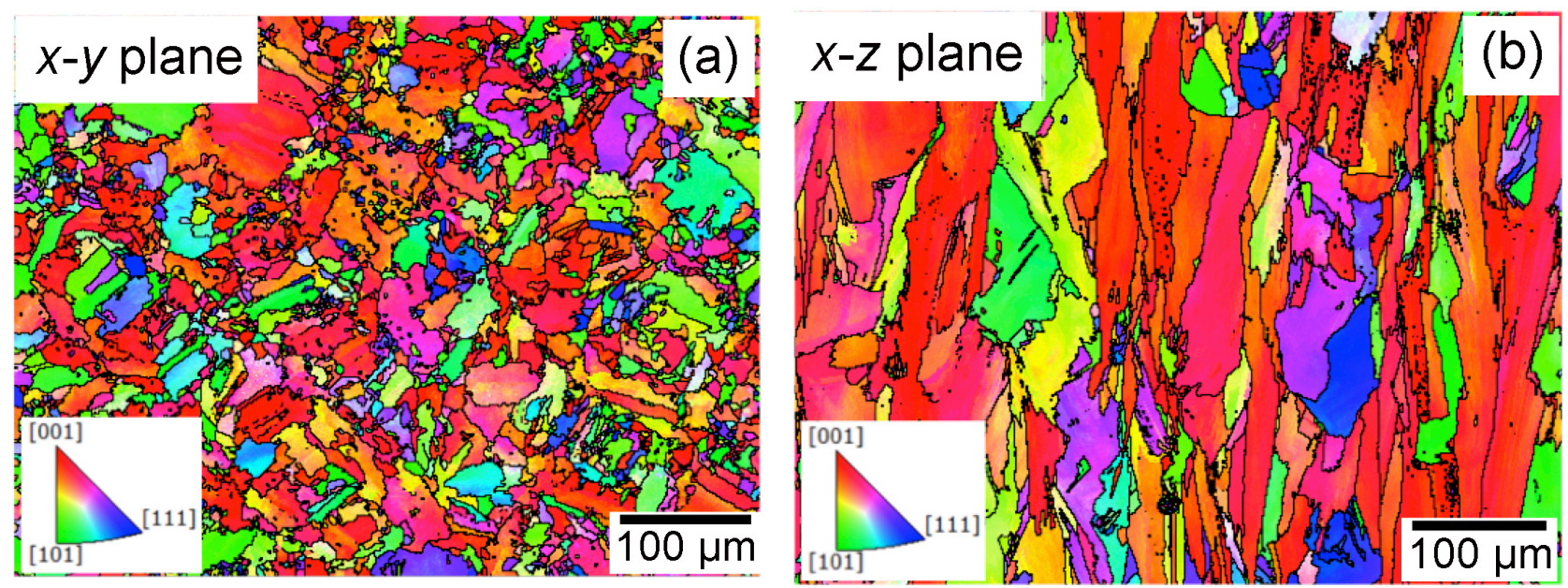

Fig.4 Inverse pole figure maps along the build direction from: (a) the $x-y$ plane and (b) the $x$ $z$ plane.

\subsection{Intra-granular Structure}

Some intra-granular features in the as-produced material were revealed by on-axis TKDFSE imaging in bright field mode, which showed diffraction contrast - see Fig.5. Relatively high dislocation densities were observed, but there was apparently no gamma prime phase. This is consistent with synchrotron X-ray diffraction observations [40] for a similar superalloy processed by selective laser melting. As indicated by the arrows, two directions of dislocation glide were apparent, corresponding to slip systems within the grain. This suggests that slip across cell boundaries was relatively easy, despite evidence [11, 41] of local chemical segregation to cell boundaries in similar materials. However, in contrast to their findings, high dislocation densities were observed here within the cells. This may be associated with lower levels of inter-cellular phases, such as Hf-rich MC carbides in CM247LC. Hence dislocations are not trapped at the cell boundaries, where those carbides are normally located. It may be noted that these high dislocation densities in the as-produced material may limit the degree of work hardening during subsequent deformation. 


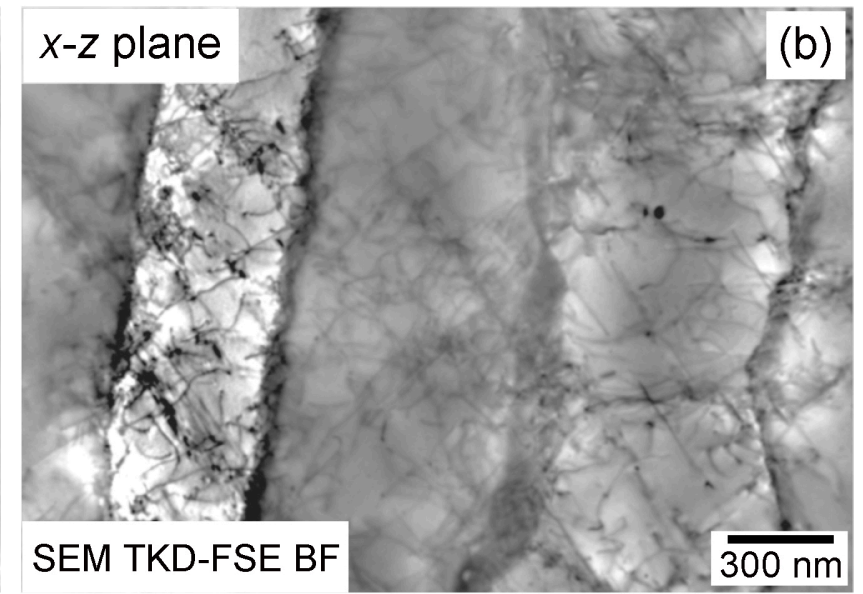

Fig.5 SEM-based on-axis transmission Kikuchi diffraction fore-scattered electron (TKD/FSE) images of a transverse (x-z) plane, at (a) low and (b) high magnification.

\subsection{Structure around Indents}

Fig.6 shows SEM micrograph of the free surface in the vicinity of an indent on a transverse $(x-y)$ section, with Fig.6(b) being a higher magnification view of the region marked in Fig.6(a). Fig.6(a) indicates that this indent is radially symmetric and this was confirmed by profilometry measurements. Fig.6(b) provides insights into how the deformation took place in these nearsurface regions around the periphery of indents. As observed previously - see Fig.7 in [29], sets of parallel lines can be seen within individual grains. These are persistent slip bands, creating physical steps on the free surface, with each set corresponding to operation of a particular slip system.
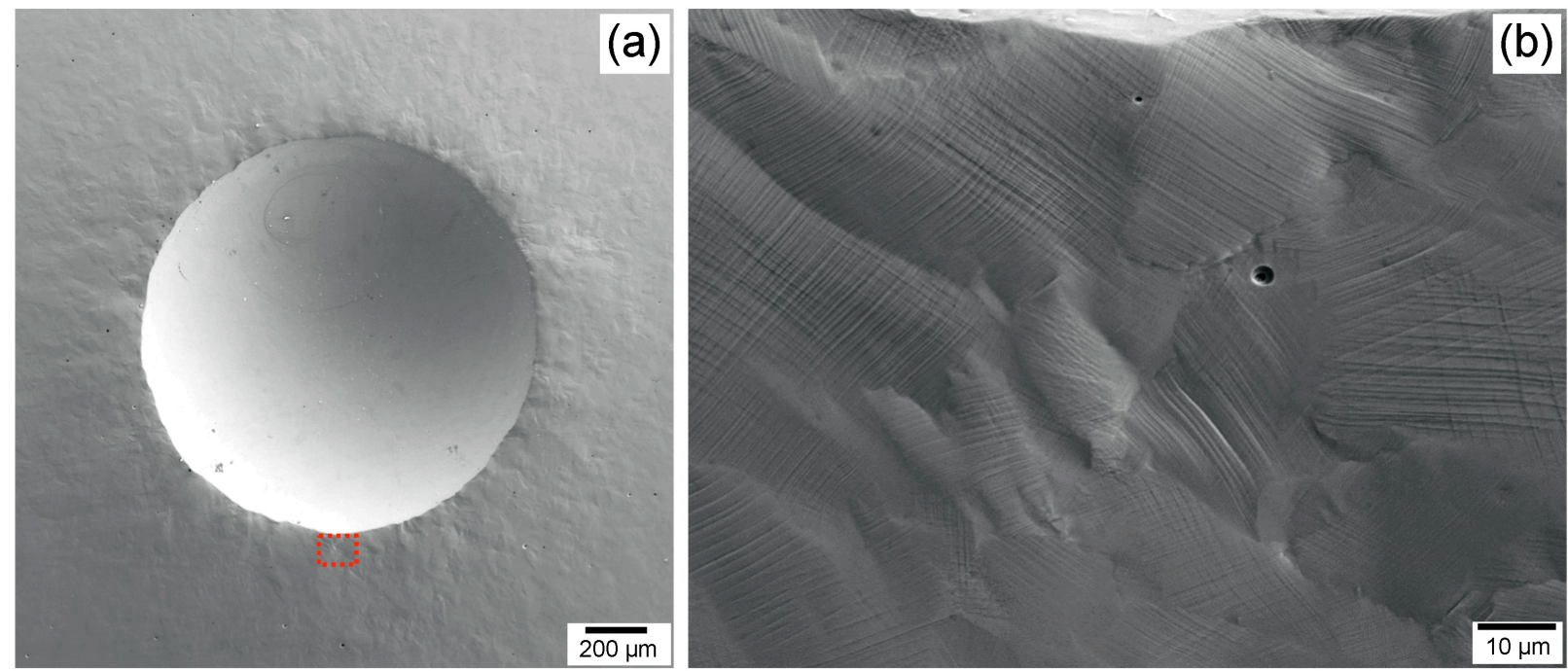

Fig.6 SEM micrographs of the region around an indent in a transverse $(x-y)$ section, at (a) low and (b) high magnification.

It can be seen that more than one system was operative in these grains, despite the fact that the plastic strains in these regions are relatively low (of the order of $1-2 \%$ ). This is a consequence of the mutual constraint that neighbouring grains exert on each other as they deform, such that they are required to undergo complex shape changes. 

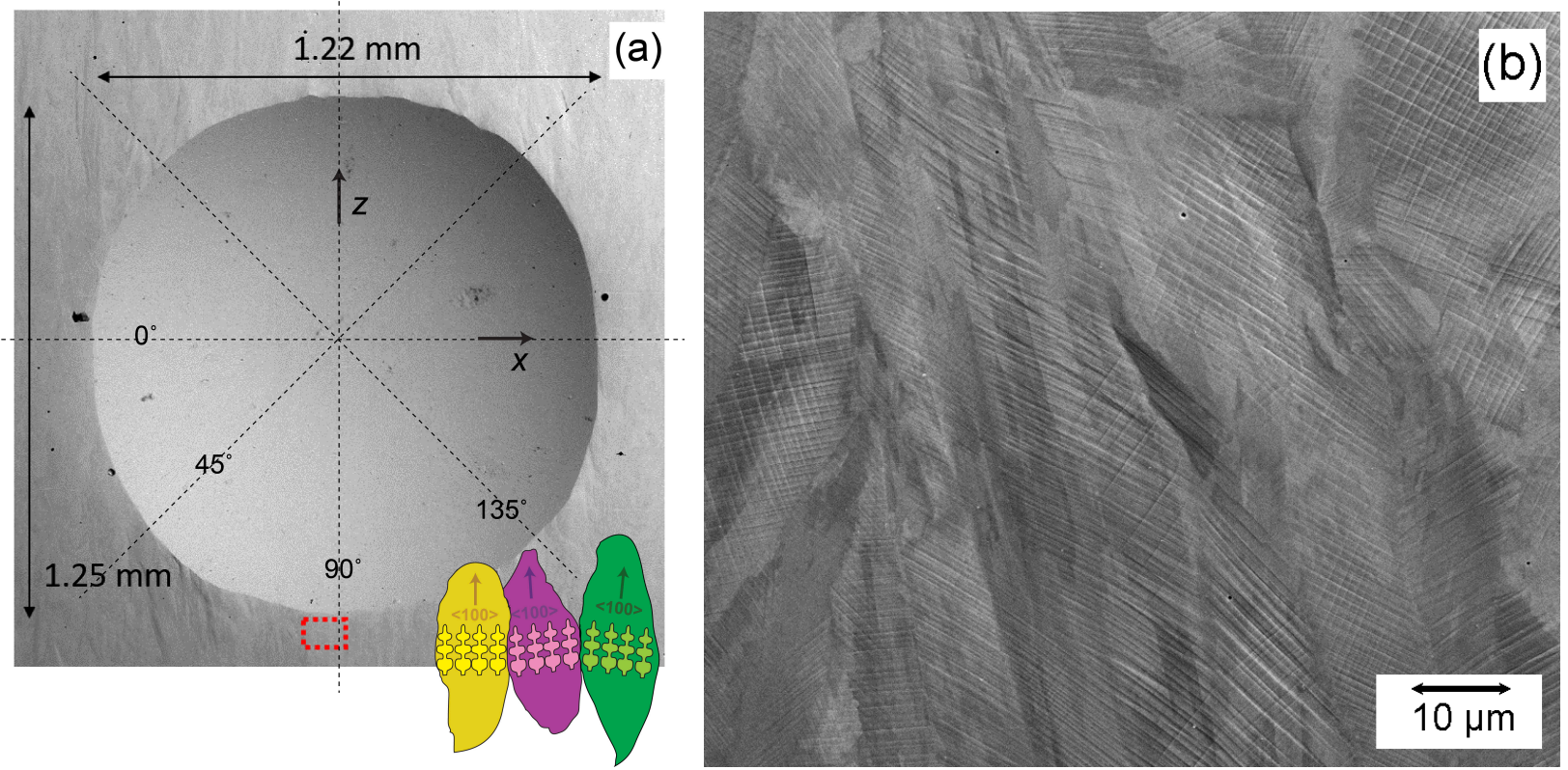

Fig.7 SEM micrographs of the region around an indent in an axial ( $x-z)$ section, at (a) low and (b) high magnification (in the location indicated by the small rectangle in (a)). The insert in Fig.7(a) is intended to convey an impression of the key features of the grain structure.

The corresponding micrographs from the axial section, shown in Fig.7, reflect slightly different behavior. It can be seen in Fig.7(a) that this indent produced is not radially symmetric. Without detailed information about the texture (or other potential sources of anisotropy, such as aligned precipitates or porosity), it is difficult to say anything properly quantitative about the shape of the indent, but it is clearly indicative of anisotropy. The shape exhibits only 2 -fold symmetry, with the response in the $z$ (build) direction being different from that in the $y$ (transverse) direction. Also apparent in Fig.7(b) is that the deformed region, while certainly not confined to a single grain, probably contains only a relatively small number of grains. Both of these effects - evidence of anisotropy and an indication that the indent straddles a relatively small number of grains - may be flagged up as potential sources of error when using the standard PIP procedure. On the other hand, the indent shape does at least give some semiquantitative information about the anisotropy. This is explored in a little more detail below in $\S 4.2$. The angles marked in Fig.7(a) are those in which profile scans were taken.

\section{Mechanical Response}

\subsection{Tensile Testing}

\subsubsection{Elastic and Plastic Deformation}

Tensile tests were carried out with the tensile axis either vertical (along the growth direction) or horizontal (transverse to the growth direction). Representative nominal stressstrain curves are shown in Fig.8. Three tests were carried out in each case. The standard deviations on stiffness, yield stress and UTS were respectively $1.1 \mathrm{GPa}, 3.5 \mathrm{MPa}$ and 13.6 MPa for the vertical sample and 3.0 GPa, 5.5 MPa and 4.3 MPa for the horizontal sample. This represents a high level of reproducibility. 


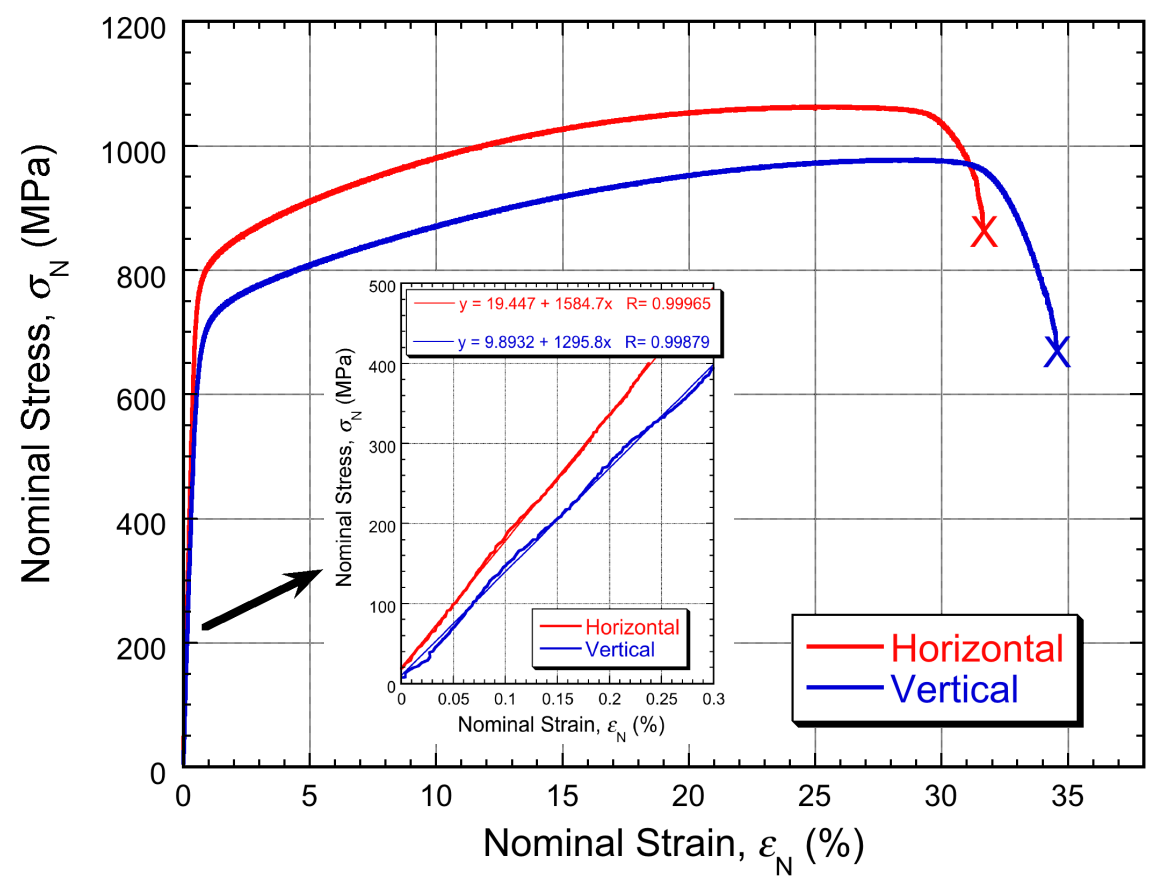

Fig.8 Typical plots of nominal stress against nominal strain from tensile testing of samples in horizontal and vertical directions.

\begin{tabular}{|c|c|c|c|c|}
\hline Sample & $\begin{array}{c}\text { Young's modulus, } \\
E(\mathrm{GPa})\end{array}$ & $\begin{array}{c}0.2 \% \text { Yield stress, } \\
\text { or (MPa) }\end{array}$ & $\begin{array}{c}\text { Ultimate Tensile } \\
\text { Strength, ouTs (MPa) }\end{array}$ & $\begin{array}{c}\text { Ductility, } \\
\varepsilon_{\mathrm{N}^{*}}(\%)\end{array}$ \\
\hline Vertical & 129 & 673 & 978 & 34.6 \\
\hline Horizontal & 158 & 775 & 1063 & 31.6 \\
\hline
\end{tabular}

Table II Summary of data from experimental tensile tests.

There is clearly some anisotropy in these responses. As shown in Table II, the yield stress and ultimate tensile strength of the vertical specimens are $100 \mathrm{MPa}$ lower than those of the horizontal samples, while the vertical specimens exhibit a slightly greater elongation to failure. These characteristics agree well with reports in the literature $[12,42,43]$ on similar testing of superalloys. Additionally, a difference in the elastic modulus between the two orientations is seen, which was also reported by Deng et al [44] for IN718. The measured stiffness was about $130 \mathrm{GPa}$ for the vertical samples and about $160 \mathrm{GPa}$ for the horizontal ones - see the inset in Fig.8. This should be considered in terms of the elastic anisotropy of single crystals of $\mathrm{Ni}$, which is known to be unusually strong. Data in Nye [45] indicate that the Young's modulus in $<111>$ is about $290 \mathrm{GPa}$, while that in $<100>$ is about $125 \mathrm{GPa}$. Of course, the samples being considered here are not single crystals (and nor are they pure $\mathrm{Ni}$ ), but they are quite strongly textured polycrystals, with a tendency for $\langle 100\rangle$ to align along the growth direction. The stiffness in the growth direction being $30 \mathrm{GPa}$ lower than that in directions transverse to this is broadly consistent with these single crystal values. It may be noted at this point that, while the FEM simulation of the test involved use of a fixed value of $200 \mathrm{GPa}$ (and a Poisson ratio of 0.33 ), the sensitivity of the outcome to these elastic constants is low, so this would be unlikely to introduce significant errors. 


\subsubsection{Necking and Fracture}

Furthermore, not only does the vertical sample have a slightly higher ductility, but it also exhibits a greater load drop (between the UTS and the nominal stress at fracture), being about $300 \mathrm{MPa}$ (compared with about $200 \mathrm{MPa}$ for the horizontal sample). The necking and fracture thus occur a little differently for the two samples. This difference is apparent in the fracture surfaces shown in Fig.9. It can be seen that the reduction in sectional area is greater for the vertical sample. If a critical true strain condition were to be used to predict fracture, then its value would be higher for the vertical sample. Moreover, the true stress at fracture was higher for the vertical sample (despite the nominal stress being lower). On the other hand, the two fracture surfaces look very similar at high magnification (Fig.9(b) and Fig.9(e)). It may be that the differences between the two necking and fracture responses are related to prior cracks in the samples, which were created by solidification and/or solid state cracking [21, 46, 47]. These tend to be inter-granular and to be largely aligned with the plane of the crack parallel to the growth direction - see Fig.9(c) and Fig.9(f). They are thus expected to open up more readily during testing in the horizontal configuration, reducing the ductility and limiting the reduction in area before fracture occurs.
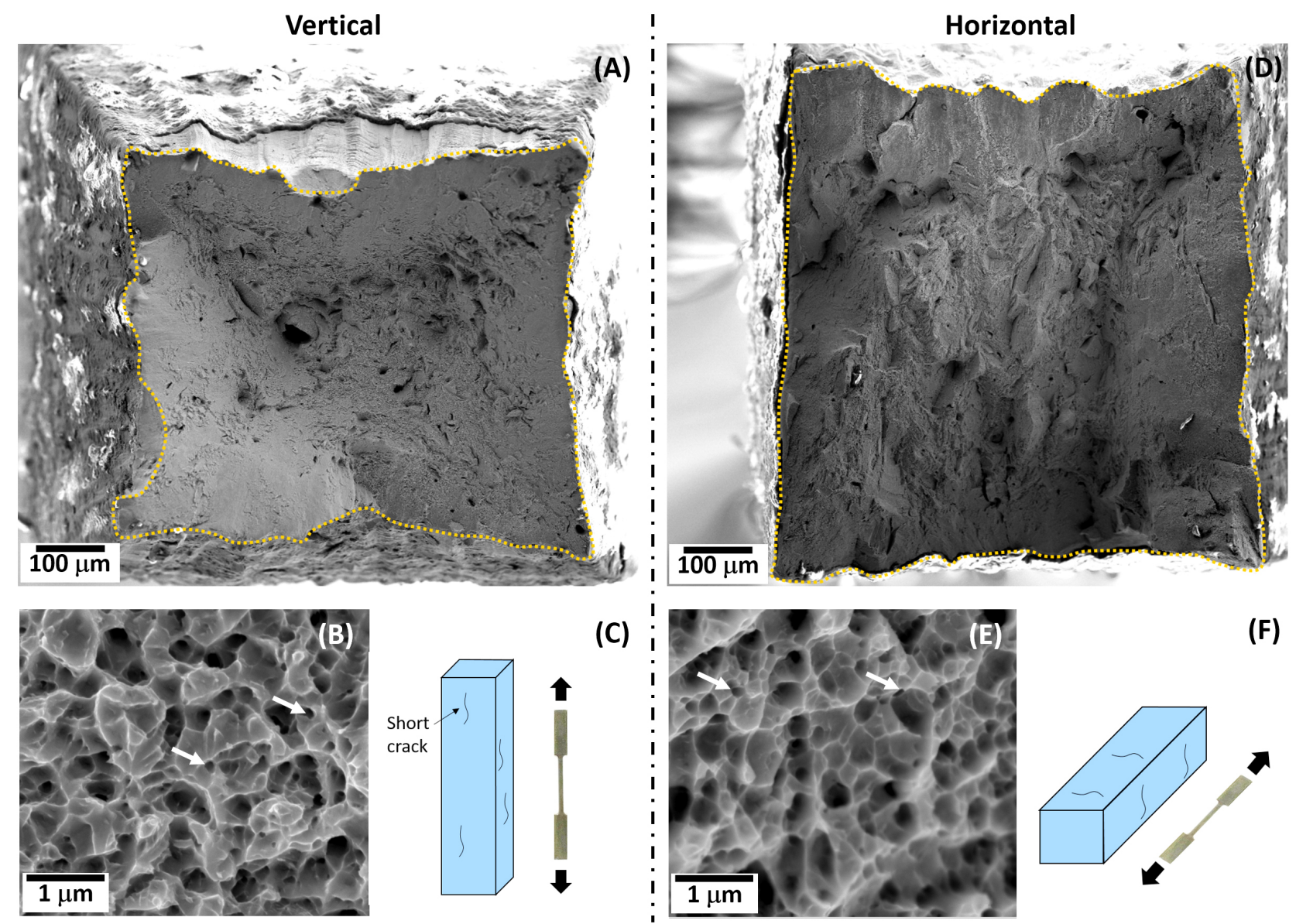

(F)

Fig.9 SEM images and schematic depictions of crack orientations for tensile testing in vertical $((A)-(C))$ and horizontal $((D)-(F))$ configurations. 


\subsection{Indentation Testing}

A comparison is shown in Fig.10(a) between experimental and (best-fit) modeled residual indent profiles, for indents created on the transverse $(x-y)$ section, using four different loads (with the same set of plasticity parameter values). It can be seen that the agreement is good for all of the loads. As well as confirming general consistency, this indicates that the plasticity characteristics do not change with depth, so that, for example, there is no near-surface layer with a different hardness or different levels of residual stress. Table III shows the set of Voce parameter values and also the value of $S_{\text {red }}$ (the goodness of fit parameter). This value (for the highest load) was about $310^{-5}$, representing excellent fidelity between measured and modeled outcomes. Fig.10(b) shows the modelled field of the (von Mises) plastic strain at the end of indentation, obtained using this set of plasticity parameter values. This indicates that the (true) plastic strains ranged up to about $60 \%$ during this test, confirming that the outcome is likely to reflect the plastic response of the material over an appropriate range of strain.

\begin{tabular}{|c|c|c|c|c|}
\hline \multirow{3}{*}{ Sample code } & \multicolumn{4}{|c|}{ Best fit Voce parameter values } \\
\cline { 2 - 5 } & $\begin{array}{c}\text { Yield stress } \\
\sigma(\mathrm{MPa})\end{array}$ & $\begin{array}{c}\text { Saturation stress } \\
\sigma_{\mathrm{s}}(\mathrm{MPa})\end{array}$ & $\begin{array}{c}\text { Characteristic } \\
\text { strain, } \varepsilon_{0}(\%)\end{array}$ & $\begin{array}{c}\text { Misfit parameter } \\
S_{\text {red }}(-)\end{array}$ \\
\hline Cub1 & 775 & 1475 & 14.3 & $3.510^{-5}$ \\
\hline
\end{tabular}

Table III Outcome of the convergence operation on the final residual indent profile in the transverse ( $x-y$ plane) sample, in the form of values of the parameters in the Voce equation for the true stress - true strain relationship.
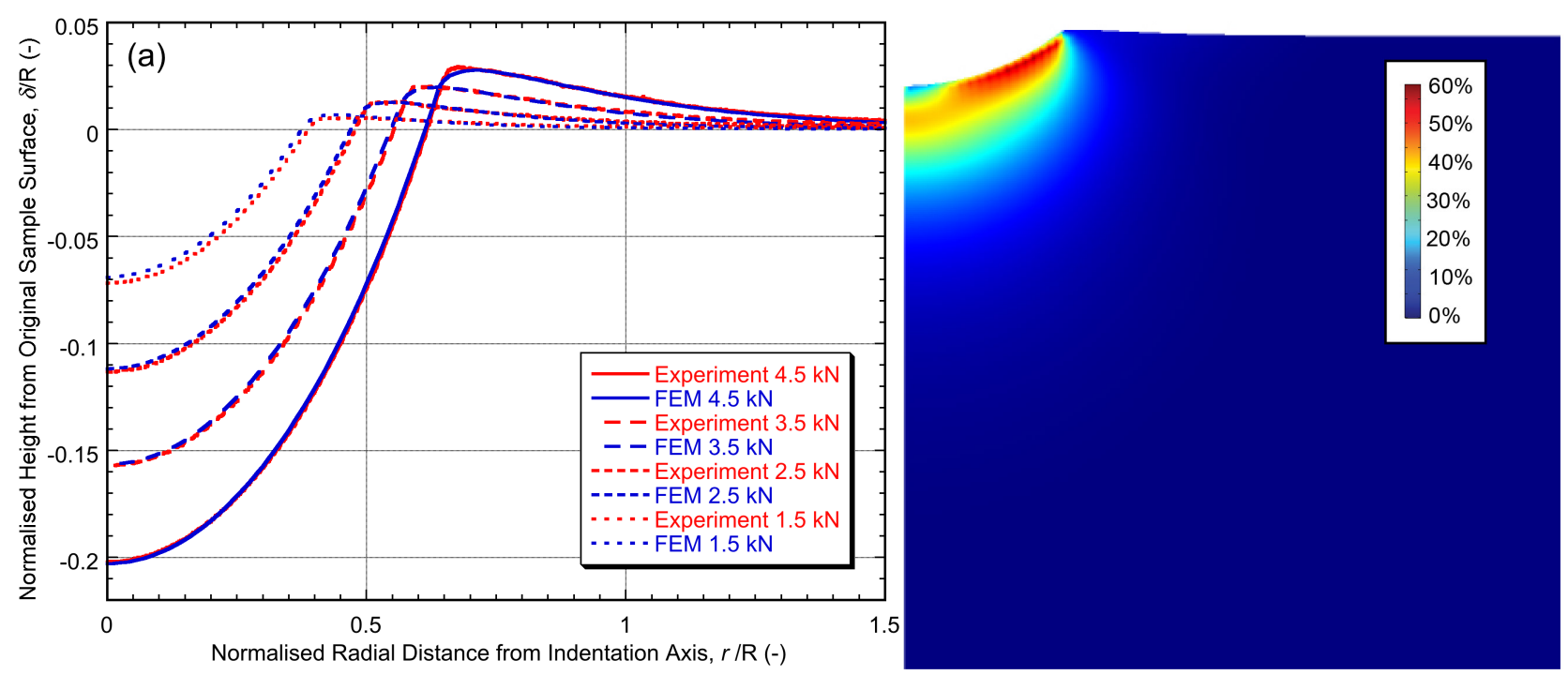

Fig.10 (a) Comparisons between measured and predicted residual indent shapes, for indentation on a transverse $(x-y)$ section, and (b) modeled field of (von Mises) plastic strain after indentation to a load of $4.5 \mathrm{kN}$.

Indents in the axial $(y-z)$ section did not exhibit radial symmetry - see Fig.7(a) - so the standard PIP algorithm cannot be employed. Fig.11 shows residual indent profiles in 4 different directions across such an indent, the scan angles corresponding to those marked on Fig.7(a). It can be seen that, while all of the scans coincide (ie there is radial symmetry) within the interior of the indent, there are significant differences in the vicinity of the "rim" of the 
"crater". In these areas, the deformed region was out of contact with the indenter, so that the deformation was less constrained. The strong texture of the sample has led to preferential activation of certain slip systems in these regions. This has created a "rim shape" exhibiting only 2-fold symmetry, with significant differences between the apparent "diameter" and "pileup height" in different directions. Furthermore, the nature of the differences is consistent with the tensile test outcomes, with the material being somewhat harder (giving less pile-up) in the $0^{\circ}(y)$ direction (ie the "horizontal" direction in the tensile test) than in the $90^{\circ}(z$ or "vertical" direction).

It should be noted that, since indentation effectively stimulates deformation in a wide range of directions, the (true stress-strain) outcome is expected to represent some kind of directionaveraged relationship. For isotropic materials, this is exactly what is required. However, for strongly anisotropic materials, such as these samples, the situation needs careful analysis. As noted above, there is not a single indent profile that can be processed in the standard way. Taking some kind of averaged profile would allow a single stress-strain curve to be obtained, but this would not necessarily correspond to an averaged stress-strain curve. A more complex modeling procedure, with more values in parameter space to be evaluated, can be envisaged, but is not yet available. On the other hand, profile data such as those in Fig.11, which can readily be obtained, do clearly indicate the presence of (plastic) anisotropy, and also give a (semi-quantitative) indication of the (in-plane) directions in which yielding and work-hardening take place more easily. This capability evidently has potential value.

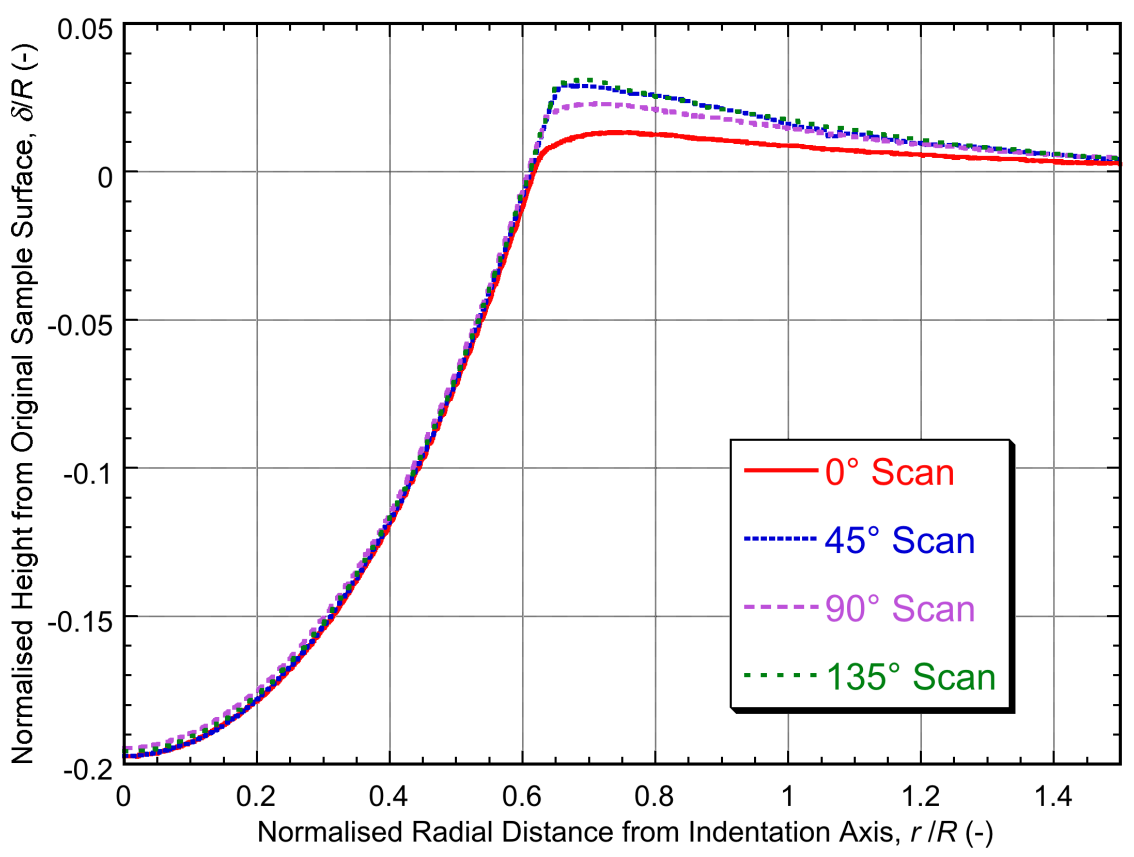

Fig.11 Residual indent profiles, measured in 4 different directions, for indentation on an axial $(y-z)$ section, after application of a load of $4.5 \mathrm{kN}$.

\subsection{Inferred Tensile Stress-Strain Curve}

For the indent on a transverse section, the inferred (true) stress-strain curve (corresponding to the derived Voce parameter values) is shown in Fig.12(a), together with the outcome of FEM simulation of the tensile test (as a plot of nominal stress against nominal strain). It can 
be seen that necking is predicted to start at just above $20 \%$ nominal strain. After that, the nominal stress drops off sharply as the neck develops, although the true stress and strain within the neck continue to increase as shown. The end point comes with rupture of the neck, shown as occurring at a true strain of about $80 \%$ in this case. The idea of fracture occurring when the true stress reaches a critical value is a common one. Fig.12(b) shows a comparison between this predicted plot and the experimental curves corresponding to the tensile axis being in "horizontal" or "vertical" directions.
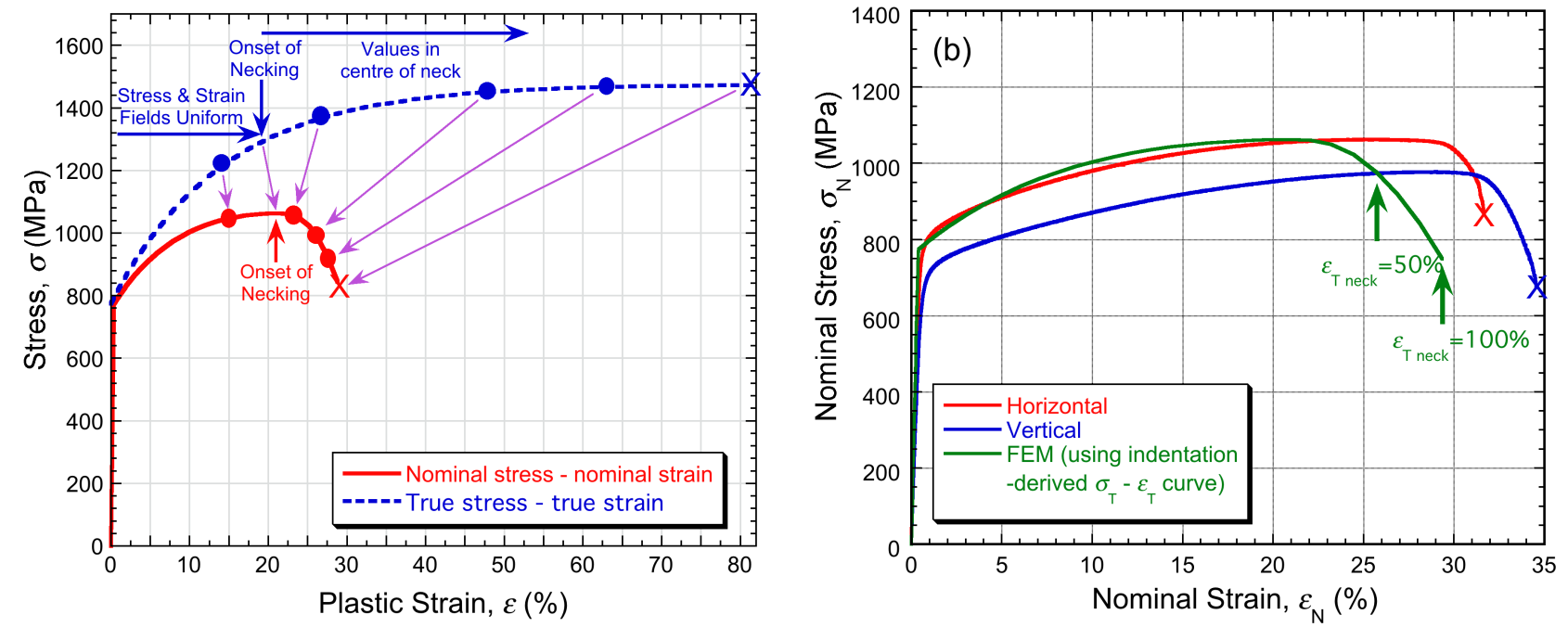

Fig.12 (a) A true stress v. true strain plot, based on the Voce parameter values in Table III, with a corresponding plot of nominal stress $v$. nominal strain, obtained by FEM simulation of a tensile test (for an aspect ratio of 14 for the gauge length), and (b) comparison between this and the two experimental plots.

It can be seen that there is a good measure of general agreement regarding both the yield stress and the work hardening characteristics. The indentation-derived plot appears to be somewhat closer to the "horizontal" curve. In fact, this is as expected, since the indentation outcome is a direction-averaged one and, considered simplistically, there is a 2:1 bias towards the horizontal directions. However, it should in any event be recognized that there is inevitably a level of uncertainty (probably of the order of $\pm 5 \%$ ) associated with both directly-measured and indentation-derived plots. The outcome here is certainly a consistent one, to a realistic level of precision.

The level of agreement regarding the necking and post-necking parts of the curve is also generally good. Prediction of the exact strain at which necking occurs is always rather problematic, since it is expected (according to the Considère criterion) to be at the peak of a nominal stress-strain plot, which often exhibits a broad plateau. Prediction of the UTS, on the other hand, is expected to be quite reliable. Furthermore, there is quite good agreement regarding the post-necking behaviour. Prediction of the actual point of fracture will always be difficult, mainly because it is virtually impossible to apply any kind of rigorous fracture mechanics approach to the final rupture event. However, the criterion of the true strain reaching a critical value in the neck is easy to apply and, as can be seen in Fig.12(b), the data are consistent in this case with the value being of the order of $60-100 \%$ - which is a plausible 
range. (It is important to note that this is very different from a "ductility" reported in the form of a nominal strain at failure, which actually depends on test sample dimensions.) It may finally be noted that the information presented in Fig.9 concerning differences between the two types of sample regarding the necking and the fracture events is relevant to the value of the critical strain at fracture that is appropriate in the two cases.

\section{Conclusions}

The following conclusions can be drawn from this work:

(a) Samples have been produced (of a particular Ni-based superalloy) using an additive manufacturing procedure. This involves a well-defined build direction, along which solidification took place, creating a columnar grain structure. These samples exhibit a strong (transversely isotropic) texture, based on alignment of the $<100>$ (easy growth) directions parallel to the build direction.

(b) Tensile testing has been carried out along both the build direction and the transverse direction. In addition, indents have been created on both transverse and axial sections, using a relatively large spherical indenter. Indent profiles have been measured and the PIP procedure applied in order to infer the true stress - true strain relationship, and hence to predict the nominal stress - nominal strain curve expected from a tensile test.

(c) It is found that the stiffness, yield stress and UTS values were all significantly higher for testing along the transverse ("horizontal") direction, compared with those for the axial ("vertical") direction.

(d) Indents produced on transverse sections were radially symmetric. Application of the standard PIP methodology to these profiles lead to a (nominal) stress-strain curve for tensile testing (of the type undertaken) that was close to those obtained experimentally, being somewhat closer to the "horizontal" curve than the "vertical" one. Since these predicted curves represent direction-averaged responses, this is what is expected. The results can therefore be taken to constitute confirmation of the reliability of the procedure.

(e) Indents on axial sections exhibited only 2-fold symmetry (rather than radial symmetry). This is as expected from the anisotropy of the plastic response in the tensile test outcomes. The indent profiles were thus different in different in-plane directions. This means that the standard PIP procedure cannot be applied. However, these profiles also were consistent with the measured anisotropy. This procedure, which is very quick and easy to carry out, could therefore be used in order to test for anisotropy and to obtain what might be regarded as a semiquantitative measure of its nature and strength.

\section{Acknowledgements}

YTT and RCR would like to acknowledge funding from Innovate UK under project number 104047. RCR is grateful for funding from the Japanese Government via the Tatara project. Relevant support for TWC has been received from EPSRC (grant EP/I038691/1) and from the Leverhulme Trust, in the form of an International Network grant (IN-2016-004) and an Emeritus Fellowship (EM/2019-038/4). Thanks are also due to Dr. A. Németh for assistance with the tensile testing. 


\section{References}

1. Frazier, W.E., Metal Additive Manufacturing: A Review. Journal of Materials Engineering and Performance, 2014. 23(6): p. 1917-1928.

2. King, W.E., A.T. Anderson, R.M. Ferencz, N.E. Hodge, C. Kamath, S.A. Khairallah and A.M. Rubenchik, Laser powder bed fusion additive manufacturing of metals; physics, computational, and materials challenges. Applied Physics Reviews, 2015. 2(4): p. 26.

3. Dehoff, R.R., M.M. Kirka, W.J. Sames, H. Bilheux, A.S. Tremsin, L.E. Lowe and S.S. Babu, Site specific control of crystallographic grain orientation through electron beam additive manufacturing. Materials Science and Technology, 2015. 31(8): p. 931-938.

4. Sames, W.J., F.A. List, S. Pannala, R.R. Dehoff and S.S. Babu, The metallurgy and processing science of metal additive manufacturing. International Materials Reviews, 2016. 61(5): p. 315360.

5. Herzog, D., V. Seyda, E. Wycisk and C. Emmelmann, Additive manufacturing of metals. Acta Materialia, 2016. 117: p. 371-392.

6. DebRoy, T., H.L. Wei, J.S. Zuback, T. Mukherjee, J.W. Elmer, J.O. Milewski, A.M. Beese, A. Wilson-Heid, A. De and W. Zhang, Additive manufacturing of metallic components - Process, structure and properties. Progress in Materials Science, 2018. 92: p. 112-224.

7. Korner, C., M. Markl and J.A. Koepf, Modeling and Simulation of Microstructure Evolution for Additive Manufacturing of Metals: A Critical Review. Metallurgical and Materials Transactions a-Physical Metallurgy and Materials Science, 2020. 51(10): p. 4970-4983.

8. Jia, Q.B. and D.D. Gu, Selective laser melting additive manufacturing of Inconel 718 superalloy parts: Densification, microstructure and properties. Journal of Alloys and Compounds, 2014. 585: p. 713-721.

9. Acharya, R. and S. Das, Additive Manufacturing of IN100 Superalloy Through Scanning Laser Epitaxy for Turbine Engine Hot-Section Component Repair: Process Development, Modeling, Microstructural Characterization, and Process Control. Metallurgical and Materials Transactions a-Physical Metallurgy and Materials Science, 2015. 46A(9): p. 3864-3875.

10. Chlebus, E., K. Gruber, B. Kuznicka, J. Kurzac and T. Kurzynowski, Effect of heat treatment on the microstructure and mechanical properties of Inconel 718 processed by selective laser melting. Materials Science and Engineering a-Structural Materials Properties Microstructure and Processing, 2015. 639: p. 647-655.

11. Divya, V.D., R. Munoz-Moreno, O. Messe, J.S. Barnard, S. Baker, T. Illston and H.J. Stone, Microstructure of selective laser melted CM247LC nickel-based superalloy and its evolution through heat treatment. Materials Characterization, 2016. 114: p. 62-74.

12. Deng, D.Y., R.L. Peng, H. Brodin and J. Moverare, Microstructure and mechanical properties of Inconel 718 produced by selective laser melting: Sample orientation dependence and effects of post heat treatments. Materials Science and Engineering a-Structural Materials Properties Microstructure and Processing, 2018. 713: p. 294-306.

13. Zhang, F., L.E. Levine, A.J. Allen, M.R. Stoudt, G. Lindwall, E.A. Lass, M.E. Williams, Y. Idell and C.E. Campbell, Effect of heat treatment on the microstructural evolution of a nickel-based superalloy additive-manufactured by laser powder bed fusion. Acta Materialia, 2018. 152: p. 200-214.

14. Panwisawas, C., Y.T. Tang and R.C. Reed, Metal 3D printing as a disruptive technology for superalloys. Nature Communications, 2020. 11(1): p. 4.

15. Tang, Y.T., C. Panwisawas, J.N. Ghoussoub, Y.L. Gong, J.W.G. Clark, A.A.N. Nemeth, D.G. McCartney and R.C. Reed, Alloys-by-design: Application to new superalloys for additive manufacturing. Acta Materialia, 2021. 202: p. 417-436.

16. Qi, H., M. Azer and A. Ritter, Studies of Standard Heat Treatment Effects on Microstructure and Mechanical Properties of Laser Net Shape Manufactured INCONEL 718. Metallurgical and Materials Transactions a-Physical Metallurgy and Materials Science, 2009. 40A(10): p. 24102422.

17.Bi, G.J., C.N. Sun, H.C. Chen, F.L. Ng and C.C.K. Ma, Microstructure and tensile properties of superalloy IN100 fabricated by micro-laser aided additive manufacturing. Materials \& Design, 2014. 60: p. 401-408.

18. Kuo, Y.L., S. Horikawa and K. Kakehi, Effects of build direction and heat treatment on creep properties of Ni-base superalloy built up by additive manufacturing. Scripta Materialia, 2017. 129: p. 74-78. 
19. Tomus, D., P.A. Rometsch, M. Heilmaier and X.H. Wu, Effect of minor alloying elements on crackformation characteristics of Hastelloy- $X$ manufactured by selective laser melting. Additive Manufacturing, 2017. 16: p. 65-72.

20.Xu, X., J.L. Ding, S.H. Ganguly and S. Williams, Investigation of process factors affecting mechanical properties of INCONEL 718 superalloy in wire plus arc additive manufacture process. Journal of Materials Processing Technology, 2019. 265: p. 201-209.

21. Han, Q.Q., Y.C. Gu, R. Setchi, F. Lacan, R. Johnston, S.L. Evans and S.F. Yang, Additive manufacturing of high-strength crack-free Ni-based Hastelloy $X$ superalloy. Additive Manufacturing, 2019. 30: p. 11.

22. Wang, Y.C. and J. Shi, Texture control of Inconel 718 superalloy in laser additive manufacturing by an external magnetic field. Journal of Materials Science, 2019. 54(13): p. 9809-9823.

23. Heinrich, C., A.M. Waas and A.S. Wineman, Determination of material properties using nanoindentation and multiple indenter tips. Int. J. Solids and Structures, 2009. 46: p. 364-376.

24. Dean, J., J.M. Wheeler and T.W. Clyne, Use of Quasi-Static Nanoindentation Data to Obtain Stress-Strain Characteristics for Metallic Materials. Acta Materialia, 2010. 58: p. 3613-3623.

25. Patel, D.K. and S.R. Kalidindi, Correlation of spherical nanoindentation stress-strain curves to simple compression stress-strain curves for elastic-plastic isotropic materials using finite element models. Acta Materialia, 2016. 112: p. 295-302.

26. Dean, J. and T.W. Clyne, Extraction of Plasticity Parameters from a Single Test using a Spherical Indenter and FEM Modelling. Mechanics of Materials, 2017. 105: p. 112-122.

27. Campbell, J.E., R.P. Thompson, J. Dean and T.W. Clyne, Experimental and Computational Issues for Automated Extraction of Plasticity Parameters from Spherical Indentation. Mechanics of Materials, 2018. 124: p. 118-131.

28. Meng, L., P. Breitkopf, B. Raghavan, G. Mauvoisin, O. Bartier and X. Hernot, On the study of mystical materials identified by indentation on power law and Voce hardening solids. International Journal of Material Forming, 2018.

29. Campbell, J.E., R.P. Thompson, J. Dean and T.W. Clyne, Comparison between stress-strain plots obtained from indentation plastometry, based on residual indent profiles, and from uniaxial testing. Acta Materialia, 2019. 168: p. 87-99.

30. Campbell, J.E., T. Kalfhaus, R. Vassen, R.P. Thompson, J. Dean and T.W. Clyne, Mechanical properties of sprayed overlayers on superalloy substrates, obtained via indentation testing. Acta Materialia, 2018. 154: p. 237-245.

31. Yonezu, A., K. Yoneda, H. Hirakata, M. Sakihara and K. Minoshima, A simple method to evaluate anisotropic plastic properties based on dimensionless function of single spherical indentation Application to SiC whisker-reinforced aluminum alloy. Materials Science and Engineering aStructural Materials Properties Microstructure and Processing, 2010. 527(29-30): p. 76467657.

32. Wang, M.Z., J.J. Wu, X.P. Zhan, R.C. Guo, Y. Hui and H. Fan, On the determination of the anisotropic plasticity of metal materials by using instrumented indentation. Materials \& Design, 2016. 111: p. 98-107.

33. Wu, J.J., M.Z. Wang, Y. Hui, Z.K. Zhang and H. Fan, Identification of anisotropic plasticity properties of materials using spherical indentation imprint mapping. Materials Science and Engineering aStructural Materials Properties Microstructure and Processing, 2018. 723: p. 269-278.

34. Tang, Y.T., P. Karamched, J.L. Liu, J.C. Haley, R.C. Reed and A.J. Wilkinson, Grain boundary serration in nickel alloy inconel 600: Quantification and mechanisms. Acta Materialia, 2019. 181: p. 352-366.

35. Voce, E., The Relationship between Stress and Strain for Homogeneous Deformation. Journal of the Institute of Metals, 1948. 74(11): p. 537-562.

36. Riley, K.F., M.P. Hobson and S.J. Bence, Mathematical Methods for Physics and Engineering Third Edition Set ed. 2006: Cambridge University Press.

37. Kim, H.S., S.H. Kim and W.S. Ryu, Finite element analysis of the onset of necking and the postnecking behaviour during uniaxial tensile testing. Materials Transactions, 2005. 46(10): p. 2159-2163.

38. Samuel, E.I., B.K. Choudhary and K.B.S. Rao, Inter-relation between true stress at the onset of necking and true uniform strain in steels - A manifestation of onset to plastic instability. Materials Science and Engineering a-Structural Materials Properties Microstructure and Processing, 2008. 480(1-2): p. 506-509.

39. Guan, Z.P., Quantitative analysis on the onset of necking in rate-dependent tension. Materials \& Design, 2014. 56: p. 209-218. 
40. Tang, Y.T., J.N. Ghoussoub, C. Panwisawas, D.M. Collins, S. Amirkhanlou, J.W.G. Clark, A.A.N. Németh, D. Graham McCartney and R.C. Reed. The Effect of Heat Treatment on Tensile Yielding Response of the New Superalloy ABD-900AM for Additive Manufacturing. 2020. Cham: Springer International Publishing.

41. Wang, X.Q., L.N. Carter, B. Pang, M.M. Attallah and M.H. Loretto, Microstructure and yield strength of SLM-fabricated CM247LC Ni-Superalloy. Acta Materialia, 2017. 128: p. 87-95.

42. Strossner, J., M. Terock and U. Glatzel, Mechanical and Microstructural Investigation of NickelBased Superalloy IN718 Manufactured by Selective Laser Melting (SLM). Advanced Engineering Materials, 2015. 17(8): p. 1099-1105.

43. Smith, D.H., J. Bicknell, L. Jorgensen, B.M. Patterson, N.L. Cordes, I. Tsukrov and M. Knezevic, Microstructure and mechanical behavior of direct metal laser sintered Inconel alloy 718. Materials Characterization, 2016. 113: p. 1-9.

44. Deng, D.Y., J. Moverare, R.L. Peng and H. Soderberg, Microstructure and anisotropic manufactured Inconel 718 and effects of post heat treatments. Materials Science and Engineering a-Structural Materials Properties Microstructure and Processing, 2017. 693: p. 151-163.

45. Nye, J.F., Physical Properties of Crystals - Their Representation by Tensors and Matrices. 1985, Oxford: Clarendon.

46. Chauvet, E., P. Kontis, E.A. Jagle, B. Gault, D. Raabe, C. Tassin, J.J. Blandin, R. Dendievel, B. Vayre, S. Abed and G. Martin, Hot cracking mechanism affecting a non-weldable Ni-based superalloy produced by selective electron Beam Melting. Acta Materialia, 2018. 142: p. 82-94.

47. Grange, D., J.D. Bartout, B. Macquaire and C. Colin, Processing a non-weldable nickel-base superalloy by Selective Laser Melting: role of the shape and size of the melt pools on solidification cracking. Materialia, 2020. 12: p. 9. 
"Profilometry-based Indentation Plastometry to obtain StressStrain Curves from Anisotropic Superalloy Components made by Additive Manufacturing"

YT Tang, JE Campbell, M Burley, J Dean, RC Reed \& TW Clyne Reviewer \#1

1) . . 6: Please explain the $B C$ imposed in more detail. It is not clear how the authors prevented lateral straining.

The BCs imposed for simulation of indentation are described fully in previous publications. The text has been expanded slightly to clarify this. (The lateral extent, and indeed the depth, of the modelled domain are large enough to ensure that there are no "edge effects".)

2) . . 6: The cracks in Fia. 3 seem to be pre-existina cracks. not indentationinduced ones. Did these pre-existina cracks grow or did cracks, including subsurface cracks, form during indentation?

They are indeed pre-existing cracks, which are often quite common in AM microstructures. In this case, they were probably solidification cracks (hot tears), at least predominantly. They did not noticeably extend during indentation and new cracks were not created. (In general, cracks only form during indentation in relatively brittle materials.) Further relevant comments are made on p.11.

3) Fig. 7a: What do the 3 inserts mean?

These is just a pictorial attempt to give an impression of the main features of the grain structure, conveying an idea of the texture (a strong tendency for $<100>$ directions to lie along the build direction) and also some grain shape elongation. The figure caption has been modified to clarify this.

4) D. 9-10: Elastic unloadina plavs a role in indentation. so the choice of $E$ in FEM (200 GPa vs 130 160 GPa) will influence the final size/shape of the indent. Whv did the authors not use some averaae $E$ value from the tensile experiments but the much higher value of $200 \mathrm{GPa}$ ?

While it's correct that elastic unloading affects the residual indent profile, the influence of the value of the Young's modulus on this is relatively small (as mentioned in the text). In fact, since (as described in \$4.1.1) single crystals of Ni exhibit pronounced elastic anisotropy, and given that $\mathrm{Ni}$ superalloy samples are often quite strongly textured, this anisotropy cannot currently be taken rigorously into account during the modelling (which is based on the material being isotropic). However, the value of $200 \mathrm{GPa}$ is a reasonable direction-averaged approximation and, in view of the low sensitivity, its use is considered acceptable. 
5) D. 11: While the explanation of the hiaher ductility is reasonable how would the authors explain the lower UTS?

There is some discussion of possible explanations in the cited papers (eg Deng et al), partly oriented around texture effects. Of course, the differences in UTS are due to differences in the plasticity characteristics (true stress - true strain curve). As with most microstructure - plasticity relationships, there is potential for high levels of complexity (involving, among other things, the texture, grain size and shape, grain boundary structure etc) and with clear scope in cases such the current one for plastic anisotropy to arise in a given material. It is beyond the scope of this paper to speculate in any detail about this.

6) Fia. 14: In the discussion of post-critical behavior. it should be considered that in tensile testina the loadina conditions araduallv chanae upon necking (toward plane strain), which limits the direct comparison of results.

The changing local conditions (stress and strain fields) during tensile testing are fully taken into account during FEM simulation of the test. What the reviewer may have in mind here is the influence of these fields on the fracture event. The simulation of fracture is actually done here in a fairly crude (albeit commonly-used) way, which is to assume that fracture occurs when a critical value is reached for the true strain (in the neck), with no account taken of whether conditions (during crack propagation) are plane stress, plane strain or anything else. Actually, treatment of the fracture event forms only a very small part of this paper, but estimating the critical true strain for fracture in this way is considered to be a potentially useful capability. In fact, Fig.12(a) has been modified slightly, so as to clarify the relationship between the true stress true strain curve and the progression of the tensile test (as recorded via the nominal stress - nominal strain plot).

7) In the whole paper there is no comment on the reproducibilitv of results. What is the scatter in Fias. 8. 10. 11. 12 and how manv indentations per specimen tvpe were made? An error column should be added to corresponding tables.

In fact, the reproducibility of these results (both the nominal stressstrain curves from tensile testing and the residual indent profiles from indentation) is high. Some information about this is included in the revised text.

8) p1: Abbreviation AM should be written out.

This has been done.

9) Fia. 2: Please indicate the growth directions and dimensions in the figure directly for convenience.

This has been done - presumably the comment refers to Fig.1, rather than Fig.2. 
10) Anart from minor issues, English language is good. But please avoid "it's" or "they're" in writing.

This has been done.

Please note that a minor change has been made to the title, so as to clarify that the material being tested is anisotropic: this is an important aspect of the coverage of the paper. 

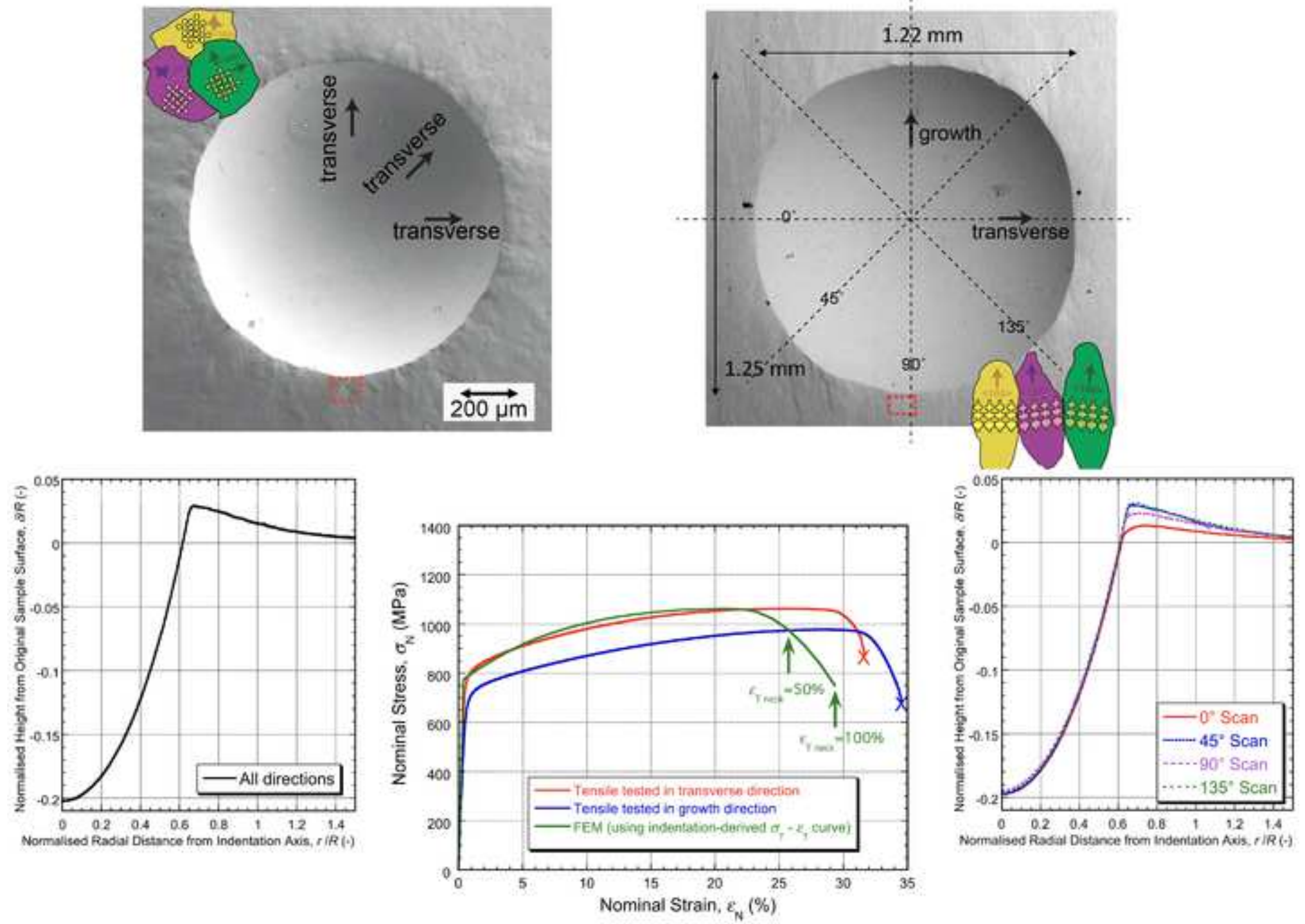


\section{Declaration of interests}

$\square \mathrm{X}$ The authors declare that they have no known competing financial interests or personal relationships that could have appeared to influence the work reported in this paper.

$\square$ The authors declare the following financial interests/personal relationships which may be considered as potential competing interests:

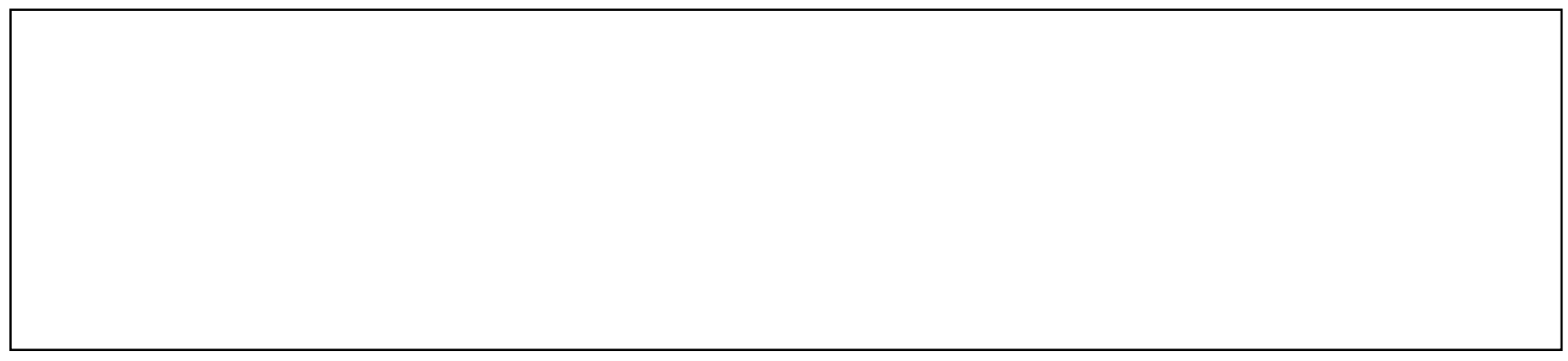

